\title{
Histological Evaluation to Study the Effects of Dental Amalgam and Composite Restoration on Human Dental Pulp: An in vivo Study
}

\author{
Neelam D. Chandwani ${ }^{\mathrm{a}}$ Mansing G. Pawar ${ }^{\mathrm{a}}$ Jagdish V. Tupkari ${ }^{\mathrm{b}}$ \\ Monal Yuwanatib \\ ${ }^{a}$ Conservative Dentistry and Endodontics and ${ }^{b}$ Oral Pathology and Microbiology, Government Dental College and \\ Hospital, Mumbai, India
}

\section{Key Words}

Dental amalgam - Composite resin - Dental pulp . Inflammatory response

\begin{abstract}
Objective: To study and compare the effects of dental amalgam and composite restorations on human dental pulp. Materials and Methods: One hundred sound premolars scheduled for orthodontic extraction were divided equally into two groups: group A, teeth restored with silver amalgam, and group B, teeth restored with composite resin. Each group was equally subdivided into two subgroups [extracted after $24 \mathrm{~h}$ (A-1 and B-1) or 7 days (A-2 and B-2)], and the histological changes in the pulp related to the two different materials at the two different intervals were studied. Results: It was found that after $24 \mathrm{~h}$, the inflammatory response of the pulp in teeth restored with amalgam and composite was similar $(p=1.00)$. However, after 7 days, the severity of the inflammatory response of the pulp in teeth restored with amalgam was less compared to that in teeth restored with composite ( $p=0.045)$. Conclusion: This study confirmed that amalgam continues to be the mechanically as well as biologically more competent restorative material. Composite could be a promising restorative material to satisfy esthetic needs for a considerable period of time. However, its biological acceptance is still in doubt.
\end{abstract}

(c) 2013 S. Karger AG, Base

\begin{tabular}{ll}
\hline KARGER & $\begin{array}{l}\text { ( ) 2013 S. Karger AG, Basel } \\
1011-7571 / 14 / 0231-0040 \$ 39.50 / 0\end{array}$ \\
E-Mail karger@karger.com & $\begin{array}{l}\text { This is an Open Access article licensed under the terms of the } \\
\text { www.karger.com/mpp }\end{array}$ \\
& $\begin{array}{l}\text { Creative Commons Attribution-NonCommercial 3.0 Un- } \\
\text { ported license (CC BY-NC) (www.karger.com/OA-license), } \\
\text { applicable to the online version of the article only. Distribu- } \\
\text { tion permitted for non-commercial purposes only. }\end{array}$
\end{tabular}

\section{Introduction}

Restorative dentistry deals with the treatment of tooth tissue defects, not only to control the disease, but also to principally restore the function as well as esthetics without compromising the biology [1]. Amalgam had always been used mostly in clinical practice, but for many years, a controversy has raged over the biocompatibility of amalgam restorations because of mercury [2]. Irrespective of the developments in the composites, the major controversies that still exist following clinical trials are its questionable functional, biological, and esthetic performance [3]. Therefore, the objective of this study was to investigate the histological response of the pulp following the restoration of teeth with the two most commonly used restorative materials in clinical practice: amalgam and composite resin.

\section{Materials and Methods}

One hundred sound premolars (maxillary and mandibular) to be extracted for orthodontic treatment were selected from 30 patients between 14 and 25 years of age who visited the Government Dental College and Hospital, Mumbai, India. Preference was given to patients requiring extraction of at least two premolars, so that one side was restored with composite resin and the other with amalgam in order to evaluate the response to both materials in one

Dr. Neelam Chandwani Bajaj c/o Smilecare Dental Clinic T-3 Godavari Sankul, 54 K.T. Nagar, Katol Road Nagpur, Maharashtra 440013 (India)

E-Mail drneelam_bajaj@ hotmail.com 
patient. Written consent was obtained from each patient or parent if the patient was below 18 years of age. This study was approved by the Ethics Committee Board of the Government Dental College and Hospital, Mumbai, India.

The selected teeth were randomly divided into two equal groups and restored with class II amalgam (group A) and composite resin (group B). The teeth were further subdivided equally into two subgroups, i.e. $24 \mathrm{~h}$ (A-1 and B-1) and 7 days (A-2 and B-2) after extraction. All clinical procedures were done by one dentist (N.D.C.) under rubber dam isolation. The cavity cutting procedure was standardized and was used for both groups.

After anaesthetizing the tooth locally, a conventional class II cavity was prepared as described previously [4]. Each cavity was prepared with a new diamond point (SF 41 ISO 109/010 and SI 46 ISO 010/012, Mani, Japan) using air rotor (NSK, Nakanishi, Japan) as the coolant [5] and high speed [6] to reduce the aggravation of inflammatory response in the pulp. As an increase in the depth of the cavity aggravates the pulp response [7], the occlusal depth was maintained at a minimum level of $1.5 \mathrm{~mm}$ from the central groove. To achieve this depth, a straight fissure diamond point was coated with self-curing acrylic at a distance of $1.5 \mathrm{~mm}$ from the tip, so that only the required length of the point was available for cutting. Each cavity was cleaned with distilled water to prevent the action of any chemicals on the pulp and was dried with sterile cotton because air blasts increase the inflammatory response [8]. The matrix band and retainer were properly adapted to the tooth using plastic wedges of uniform sizes. For this study, the following materials were used: Dispersalloy (Dentsply), which is high in copper [9], an admixture of lathe-cut and spherical silver copper eutectic particles, and posterior composite (SureFil, Dentsply) filled $82 \%$ by weight ( $65 \%$ by volume) with a blend of fused silica and barium fluoroalumino borosilicate glasses (average particle size $0.8 \mu \mathrm{m}$ ). Cavity varnish was applied to the walls of each cavity in groups A-1 and A-2 [10]. Manipulations of amalgam were done using an automatic amalgamator (Mixalloy, Rhoas) for each mix (0.06 $\mathrm{g}$ of this alloy triturated with $0.06 \mathrm{~g}$ of mercury for $10 \mathrm{~s}$ ), condensed incrementally by hand followed by carving and finishing of the restoration. As all procedures were done by the same operator (N.D.C.), the condensation pressure was considered to be the same in all cavities and therefore also the pulp response. All amalgam restorations were intentionally left unpolished to prevent inadvertent changes in the response due to polishing [11], and as much finishing as possible was done during carving of the restoration.

For restoration of teeth with composite resin (group B), all cavities were etched using 36\% phosphoric acid (DeTrey Conditioner 36 , Dentsply) for $15 \mathrm{~s}$ to improve marginal integrity because pulp reactions to acid etchants have generally been rated as mild to moderate $[12,13]$. Following thorough rinsing and drying of the cavity, a bonding agent (Prime and Bond NT, Dentsply) was applied followed by $20 \mathrm{~s}$ of curing using halogen light (CU-100, Unicorn). It was confirmed by radiometer that the light intensity of the device was not less than $400 \mathrm{~mW} / \mathrm{cm}^{2}$, as a low intensity has a poor curing capacity [14]. The teeth were restored with composite resin at an increment of not more than $2 \mathrm{~mm}$ each time. Each increment was cured for $40 \mathrm{~s}$ according to the manufacturer's instructions (http:// www.surefilsdrflow.com/sites/default/files/SureFil_Technical_ Manual.pdf). Additional curing was done over the restoration from all sides. Minor finishing, if required, was done to ensure occlusal integrity using finishing points for composite (Shofu). Necessary postoperative instructions were given to each patient of both groups.

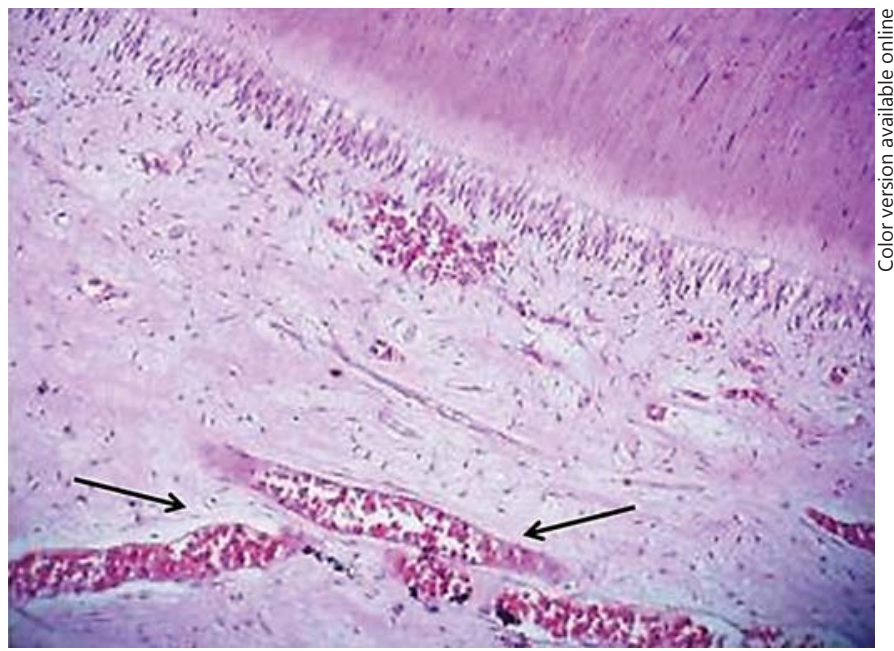

Fig. 1. Photomicrograph of amalgam after $24 \mathrm{~h}$ showing a number of dilated and engorged blood vessels suggestive of marked hyperemia.

The patients were called after $24 \mathrm{~h}$ and asked about any postoperative sensitivity or any other discomfort they might have experienced. Immediately after extraction, the teeth were placed in $10 \%$ neutral buffered formalin for $96 \mathrm{~h}$. After decalcification in 5\% formic acid, the teeth were routinely processed, serially sectioned and stained with hematoxylin and eosin (HE) for histopathological interpretations. The entire histological processing was done in a professional laboratory by the coauthors M.Y. and J.V.T. They were blinded as to which teeth were restored with amalgam or composite. The inflammatory response of the pulp was evaluated as mild, moderate, and severe according to the criteria described previously $[15,16]$. The histological observations of the two materials at a postoperative interval of $24 \mathrm{~h}$ and 7 days were compared.

\section{Results}

The 24-hour postoperative histological evaluation of the 25 teeth restored with amalgam (group A-1) showed mild pulp response in 8 (32\%), moderate pulp response in $12(48 \%)$ (fig. 1), and severe inflammatory pulp response in $5(20 \%)$ teeth. The corresponding inflammatory response of the 25 teeth restored with composite (group B-1) was as follows: mild pulp response in 7 (28\%), moderate pulp response in 13 (52\%), and severe pulp response in $5(20 \%)$. The difference in pulp response to both materials at $24 \mathrm{~h}$ was statistically insignificant $(p=1.00)$.

The 7-day postoperative histological evaluation of the 25 teeth restored with amalgam (group A-2) showed 15 (60\%) teeth with mild response and $10(40 \%)$ teeth with 


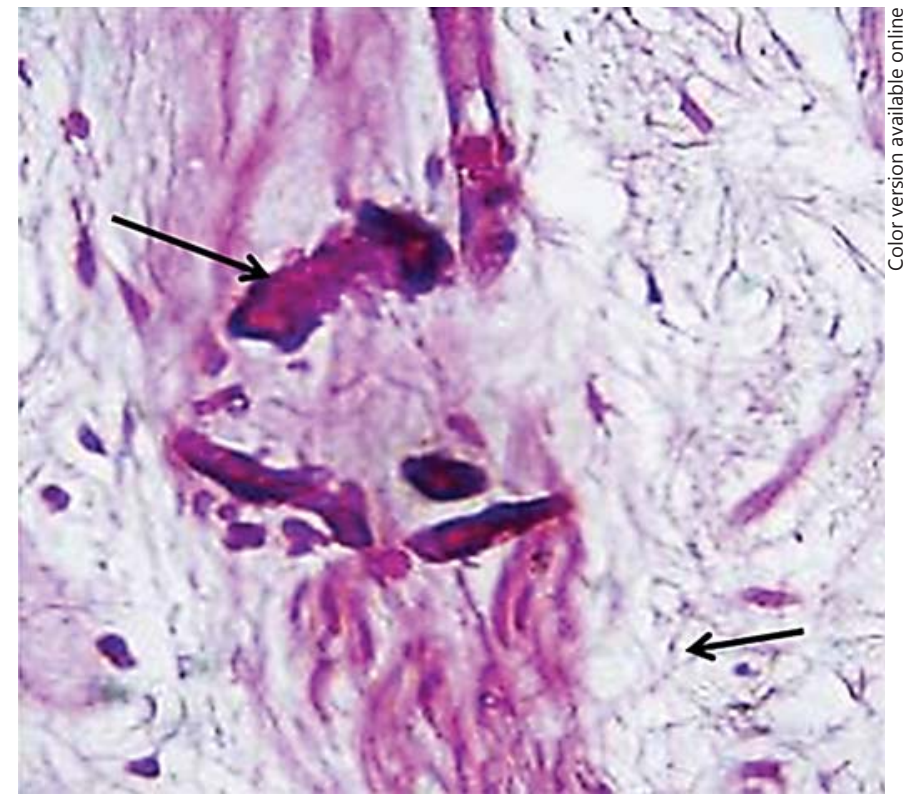

Fig. 2. Photomicrograph of amalgam after 7 days showing foci of calcification and collagen fiber bundles. HE, $\times 40$.

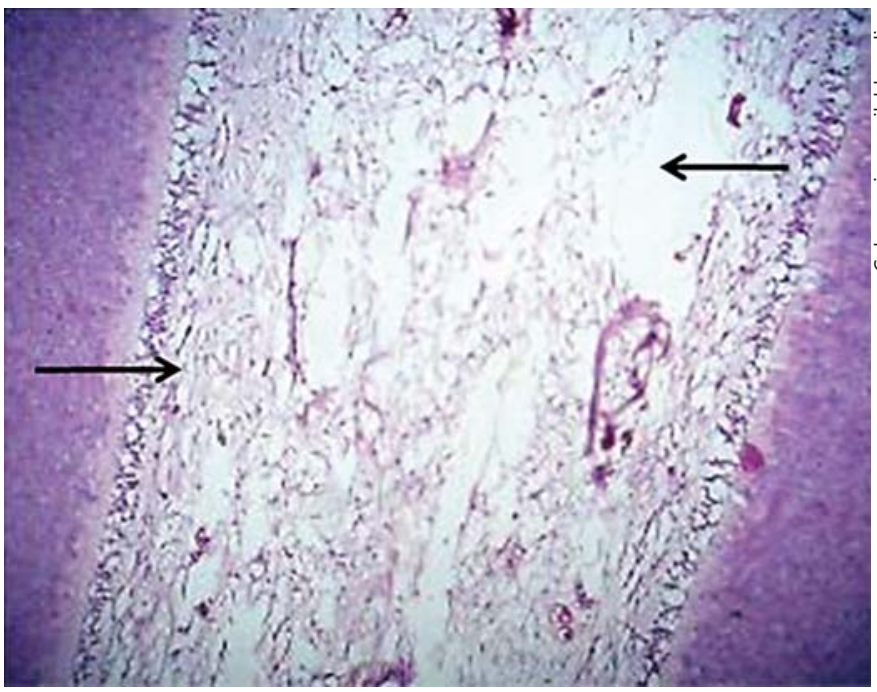

Fig. 4. Photomicrograph of composite after 7 days showing moderate inflammatory cell infiltration along with abscess in the cavity.

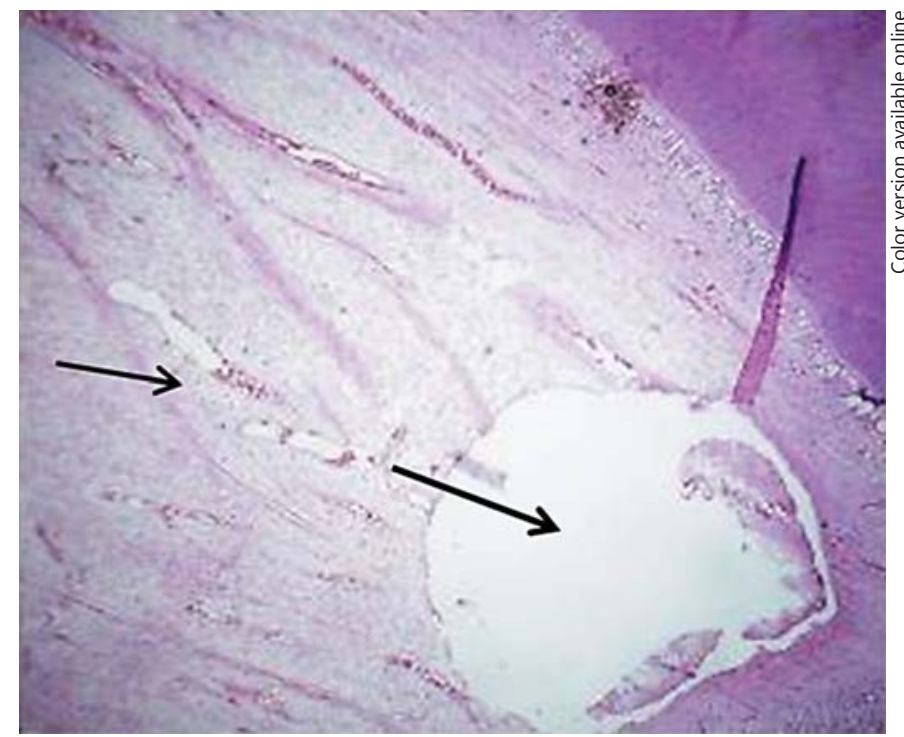

Fig. 3. Dilated blood vessels with intravascular elements along with fibrosis and cavitation suggest severe response to composite after 7 days.

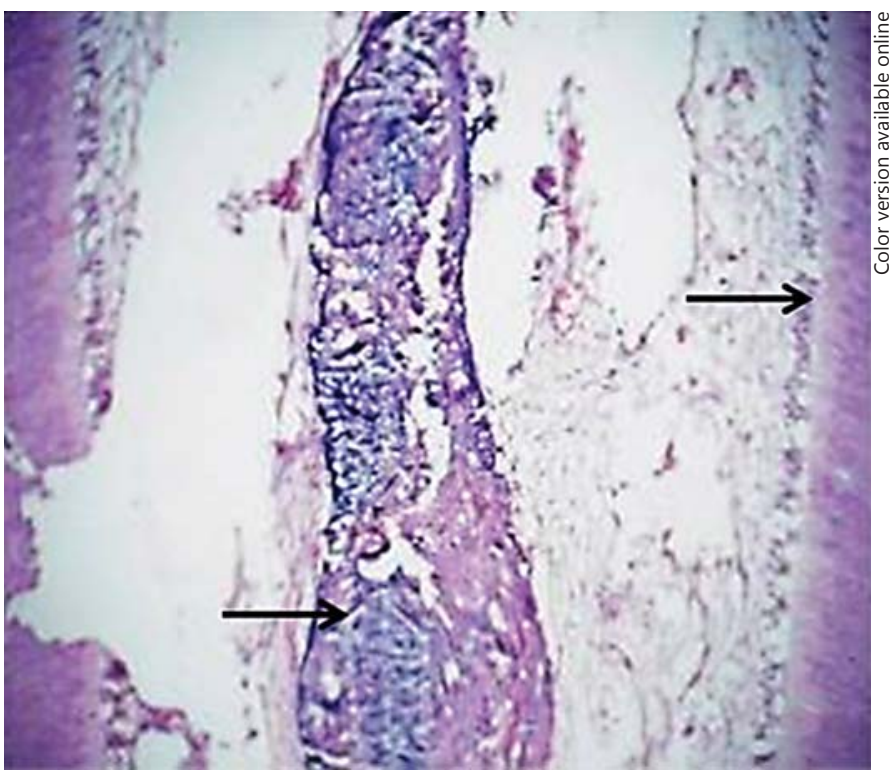

Fig. 5. Photomicrograph of composite after 7 days showing disintegrated odontoblastic layer with focal areas of necrosis. HE, $\times 40$. 
moderate to severe response. Fibrosis (fig. 2) was evident in almost $8(32 \%)$ teeth and abscess in 2 teeth, and necrosis was evident only in 3 of 25 teeth.

The corresponding response of the 25 teeth restored with composite (group B-2) showed mild inflammatory response in 7 (28\%), moderate inflammatory response in $12(48 \%)$, and severe inflammatory response in $6(24 \%)$ (fig. 3). Special features were the number of abscesses (fig. 4) and necrosis (fig. 5) in 8 (32\%) of the 25 teeth; fibrous bands were not seen in the slides of this group.

\section{Discussion}

The results after $24 \mathrm{~h}$ indicate that whether the teeth were restored with amalgam or composite, $68-72 \%$ of teeth in each group (A-1 and B-1) exhibited similar inflammatory response of the pulp at a moderate to severe degree. Because the procedure for the preparation of the cavity was similar in both groups, etiological factors other than cavity preparation that contributed to the severity of the initial inflammatory response could be: the effect of local anesthesia [17], condensation pressure [18] and thermal conductivity of amalgam [19], micro-leakage between the tooth and restoration [20], and tooth extraction. Therefore, the immediate irritation of the pulp after $24 \mathrm{~h}$ could be attributed mostly to cavity preparation and trauma due to manipulation as previously reported [17-20], irrespective of the type of material used.

There was a significant reduction in the severity of inflammatory response of the pulp in amalgam after 7 days (A-2) as compared to composite (B-2). Seven days are considered to be a sufficient time elapsed to avoid the inclusion of transient pulp inflammatory activity resulting from cavity preparation and manipulation trauma. It is also expected that as time passes, the pulp inflammation should subside, and if this does not occur, the chang- es seen in the later postoperative time intervals can mostly be attributed to the continuous irritation from the material [21].

The evidence of fibrosis in $32 \%$ of teeth restored with amalgam (A-2) is a proof that the healing potential of the pulp was increased, which could be attributed to the inertness of amalgam and its better sealing properties [10]. Various other studies [22, 23] have also demonstrated mild inflammatory pulp reactions under cavities restored with amalgam. However, no such evidence of healing was evident in any tooth restored with composite. On the contrary, necrosis and abscesses were evident in almost $32 \%$ of teeth of group B-2, which is a sign of aggravation of the inflammatory response. This can be attributed to the marginal leakage which is the result of polymerization shrinkage of composite resin [24], bacterial penetration beneath composite restoration [25, 26], its dimensional instability in the oral environment, curing method [27], restoration technique [28], and to some extent apoptosis [29] and cell death [30] through the seepage of uncured monomer in the pulp, and to their sealing and adhesion characteristics with cavity walls as well. As this is a shortterm study, the results need not have been the same if the study was extended for a longer postoperative duration. Although this method represents a practical possibility for the preliminary evaluation of a new filling material, more information is needed to determine the progressive or reparative character of the initial changes.

\section{Conclusion}

This study confirmed that amalgam continues to be the mechanically as well as biologically more competent material for restoration of teeth where esthetics may not be of primary concern. Composite could be a promising restorative material to satisfy esthetic needs for a considerable period of time.

\section{References}

1 Hargreaves KM, Goodis HE, Seltzer S (eds): Seltzer and Bender's Dental Pulp. Quintessence Publishing, 2002.

-2 Uçar Y, Brantley WA: Biocompatibility of dental amalgams. Int J Dent 2011;2011: 981595.

$>3$ Christensen GJ: Remaining challenges with class II resin-based composite restorations. J Am Dent Assoc 2007;138:1487-1489.
4 Black GV: A Work on Operative Dentistry. Chicago, Medico-Dental Publishing, 19471948.

7 Hasler JE, Mitchell DF: Painless pulpitis. J Am Dent Assoc 1970;81:671-677.

$\checkmark 6$ Stanley HR: Dental iatrogenesis, part 2. Dent Today 1995; 14:76-81.

$>7$ Lee SJ, Walton RE, Osborne JW: Pulp response to bases and cavity depths. Am J Dent 1992;5:64-68.

\footnotetext{
8 Hirvonen T, Ngassapa D, Närhi M: Relation of dentin sensitivity to histological changes in dog teeth with exposed and stimulated dentin. Proc Finn Dent Soc 1992;88(suppl 1):133141.

>9 Marshall SJ, Marshall GW Jr: Dental amalgam: the materials. Adv Dent Res 1992;6:9499.
}

Effects of Dental Amalgam versus

Composite Restoration
Med Princ Pract 2014;23:40-44 DOI: $10.1159 / 000355607$ 
10 Going RE: Reducing marginal leakage: a review of materials and techniques. J Am Dent Assoc 1979;99:646-651.

11 Cooley RL, Barkmeier WW, White JH: Heat generation during polishing of restorations. Quintessence Int Dent Dig 1978;9:77-80.

$\checkmark 12$ Nayyar S, Tewari S, Arora B: Comparison of human pulp response to total-etch and selfetch bonding agents. Oral Surg Oral Med Oral Pathol Oral Radiol Endod 2007;104:45-52.

13 De Souza Costa CA, De Nascimento AB, et al: Response of human pulps following acid conditioning and application of a bonding agent in deep cavities. Dent Mater 2002;18:543-551.

14 Tate WH, Porter KH, Dosch RO: Successful photocuring: don't restore without it. Oper Dent 1999;24:109-114.

15 Dummer PM, Hicks R, Huws D: Clinical signs and symptoms in pulp disease. Int Endod J 1980;13:27-35.

16 Murray PE, About I, Lumley PJ, et al: Human odontoblast cell numbers after dental injury. J Dent 2000;28:277-285.

17 Murray PE, About I, Lumley PJ, et al: Postoperative pulpal and repair responses. J Am Dent Assoc 2000;131:321-329.
18 Odor TM, Pitt Ford TR, McDonald F: Adrenaline in local anaesthesia: the effect of concentration on dental pulpal circulation and anaesthesia. Endod Dent Traumatol 1994;10: 167-173.

19 Swerdlow H, Stanley HR: Response of the human dental pulp to amalgam restorations. Oral Surg Oral Med Oral Pathol 1962;15:499508.

20 Stanley HR: Effects of dental restorative materials: local and systemic responses reviewed. J Am Dent Assoc 1993;124:76-80.

21 Torstenson B, Brännström M: Pulpal response to restoration of deep cavities with high-copper amalgam. Swed Dent J 1992;16: 93-99.

22 Stanley HR: Design of a human pulp study part I. Oral Surg 1968;25:633-647.

23 Manley EB: Experimental investigation into the early effects of various filling materials on the human pulp (Section of Odontology). Proc R Soc Med 1941;34:693-706.

24 Davidson CL, Feilzer AJ: Polymerization shrinkage and polymerization shrinkage stress in polymer-based restoratives. J Dent 1997;25:435-440.
25 Murray PE, Hafez AA, Smith AJ, et al: Bacterial microleakage and pulp inflammation associated with various restorative materials. Dent Mater 2002;18:470-478.

26 Murray PE, Windsor LJ, Hafez AA, et al: Comparison of pulp responses to resin composites. Oper Dent 2003;28:242-250.

27 Deliperi S, Bardwell DN: An alternative method to reduce polymerization shrinkage in direct posterior composite restorations. J Am Dent Assoc 2002;133:1387-1398.

28 Radhika M, Sajjan GS, Kumaraswamy BN: Effect of different placement techniques on marginal microleakage of deep class-II cavities restored with two composite resin formulations. J Conserv Dent 2010;13:9-15.

29 Mantellini MG, Botero TM, Yaman P, et al Adhesive resin induces apoptosis and cell-cycle arrest of pulp cells. J Dent Res 2003;82: 592-596.

30 Costa CA, Vaerten MA, Edwards CA, et al: Cytotoxic effects of current dental adhesive systems on immortalized odontoblast cell line MDPC-23. Dent Mater 1999;15:434-441. 